\title{
ANÁLISE DO DISCURSO NA FORMAÇÃO EM SERVIÇO DOS GESTORES ESCOLARES
}

\author{
ANALYSIS OF SPEECHES IN THE TRAINING IN SERVICE OF SCHOOL MANAGERS
}

Marcelo do Nascimento
Doutorando pela UNICAMP - Universidade de Campinas. Mestre em Educação pela UNITAU - Universidade de
Taubaté.
marcelo.jirre@gmail.com

Alessandro Luiz de Oliveira Mestre em Educação pela UNITAU - Universidade de Taubaté, Professor e Coordenador de Curso no Instituto Federal de Educação, Ciência e Tecnologia de São Paulo. alessandro.oliveira@ifsp.edu.br

\begin{abstract}
Rachel Duarte Abdala
Licenciada e bacharel em História pela Universidade de São Paulo. Mestre (2003) e Doutora (2013) pela Universidade de São Paulo. Docente do Curso de História da Universidade de Taubaté (Unitau). Líder do Núcleo de Pesquisa em História da UNITAU. Membro do Núcleo Interdisciplinar de Estudos e Pesquisas em História da Educação (NIEPHE) da Universidade de São Paulo. Coordenadora do subprojeto de História do Programa Institucional de Bolsas de Incentivo à Docência (PIBID) na Universidade de Taubaté. Docente permanente do Programa de Mestrado em Desenvolvimento Humano da UNITAU. rachel.abdala@gmail.com
\end{abstract}

Resumo: Neste artigo descrevem-se análises a partir de processo investigativo sobre a mediação epistemológica de um Programa de Formação em Serviço oferecido a gestores escolares de um município do vale do Paraíba paulista. Os objetivos propostos foram: reconstituir a estrutura metodológica do referido Programa, identificar a linha epistemológica adotada, identificar e analisar os discursos dos gestores escolares e formadores institucionais, e as políticas e ideologias adotadas. Utilizaram-se como instrumentos a análise documental, entrevistas a partir da História Oral e Análise do Discurso segundo Eni Orlandi e Michael Foucault. Foram mobilizados os campos epistemológicos de administração e gestão, gestão escolar, gestão democrática, função social da escola, qualidade e formação em serviço. Como resultado, observou-se um discurso estritamente alinhado com a política de gestão pública gerencial e economicista e uma ruptura epistemológica entre os campos técnico e político da Gestão Escolar.

Palavras chave: Formação em serviço. Gestão escolar. Político.

Abstract: This article aims to describe analyzes based on an investigative process about the epistemological mediation of an In-Service Training Program offered to school managers in a municipality in Vale do Paraíba Paulista. The proposed objectives were to reconstitute the methodological structure of this program, to identify the epistemological line adopted, and finally to identify and analyze the discourses of school administrators and institutional trainers, and by what policies and ideologies these speeches are constituted. To this end, we use as instruments the documentary analysis and interviews from Oral History, and Discourse Analysis according to Eni Orlandi and Michael Foucault. We mobilize the epistemological fields of administration and management, school management, democratic management, social function of the school, quality and in-service training. As a result, we observed a discourse strictly aligned with the managerial and economical public management policy and an epistemological rupture between the technical and political fields of School Management.

Keywords: Training in service. School management. Politica

\section{Introdução}

Propôs-se percorrer um caminho investigativo basicamente em duas frentes: coleta de dados em documentos e realização de entrevistas e análise do material coletado. O objetivo geral foi entender como um programa de formação em serviço de gestores escolares de um município selecionado promove a mediação entre campos epistemológicos de gestão e os gestores escolares. 
Utilizou-se a História Oral para reconstituir o Programa de Formação em Serviço a partir das entrevistas realizadas e dos documentos investigados. Optou-se pela História Temática, dentre outras duas modalidades propostas por Meihy (1994): História de vida e História de tradição.

\begin{abstract}
Uma questão importante é que a história oral possibilita captar as experiências elaboradas por indivíduos pertencentes a categorias sociais cujas percepções e intervenções geralmente são excluídas da história oficial e da documentação oficial das organizações [...]. Pode ser vista como um modo de construir o conhecimento e reconstituir a identidade e a história recente desses grupos diante dos processos sociais internos às organizações e do processo de globalização (ISCHIKAWA, SANTOS, 2006, p. 13).
\end{abstract}

A partir das entrevistas gravadas e dos documentos analisados, adotou-se a Análise do Discurso como método de interpretação dos discursos para identificar ideologias e condições de produção, tendo como referencial teórico basicamente o pensamento de Eni P. Orlandi e Michael Foucault.

Ao analisarmos o discurso, estaremos inevitavelmente diante da questão de como ele se relaciona com a situação que o criou. A análise vai procurar colocar em relação ao campo da língua (suscetível de ser estudada pela Lingüística) e o campo da sociedade (apreendida pela história e pela ideologia) (GREGOLIN, 1995, p. 17).

Para Foucault (1996), o discurso antecede aquele que o toma, sem saber que, de fato, é tomado por ele, e as formações discursivas determinam as relações de poder que está sempre em jogo. Há uma ordem que disciplina os discursos e determina quem está autorizado a discursar e sobre o que discursar, por meio de dispositivos externos e internos de exclusão e legitimação.

Já Orlandi (1999), sobre a análise do discurso, afirma que o pesquisador deve trabalhar no limite da interpretação, porque não se coloca como observador neutro, mas sujeito as condições de produção do seu contexto. Dessa forma, para assumir uma condição de análise com certo deslocamento de sua própria posição, deve atuar no entremeio entre os discursos e uma base teórica sobre o objeto de pesquisa.

[...] trata-se da teoria, no sentido de que não há análise de discurso sem mediação teórica permanente, em todos os passos da análise, trabalhando a intermitência entre descrição e interpretação que constituem, ambas, o processo de compreensão do analista. É assim que o analista "encara" a linguagem (ORLANDI, 1999, p. 62).

Assim, aceitou-se o desafio de investigar e identificar, a partir das vozes não registradas na história oficial, por meio da Histórica Oral, o que revelam os discursos dos gestores e formadores entrevistados sobre o Programa de Formação em serviço, no qual são sujeitos.

Iniciou-se pela análise dos documentos. Para tanto, foram solicitados solicitamos planos, atas, avaliações, devolutivas e orientações, mas houve a informação de que não existiam esses documentos relacionados aos processos do Programa de Formação em Serviço de Gestores Escolares. Foi disponibilizado na condição de documento formal um grupo de slides em PowerPoint, que cumpriu a função de portfólio de ações e projetos da Secretaria Educação no ano de 2017. Dentre essas ações, ocorreram encontros formativos com diferentes agrupamentos, destinados ao Gestor Escolar, ao Vice-diretor e ao Professor Coordenador. 
Sequenciando a pesquisa, foram entrevistados 8 Gestores Escolares (2 de cada segmento da Educação Básica): 2 da educação Infantil, 2 do Ensino Fundamental $1^{\circ}$ Ciclo $\left(1^{\circ}\right.$ ao $5^{\circ}$ ano $), 2$ do Ensino Fundamental $2^{\circ}$ Ciclo ( $5^{\circ}$ ao $9^{\circ}$ ano) e 2 do Ensino Médio. A escolha foi a partir da indicação da Secretaria Municipal de Educação (SME) dos gestores considerados com melhor desempenho. Foram entrevistados também 3 Formadores que atuam na SME e que, em diferentes graus, concebem, operacionalizam e avaliam o referido Programa.

$\mathrm{Na}$ Rede de Ensino estudada existem hoje cerca de 2.300 professores e 41 mil alunos, atendidos em 131 unidades escolares: 69 creches e berçários, 53 escolas de ensino fundamental, 1 escola de ensino médio, além de projetos como Educação para Jovens e Adultos - EJA.

Ao final do processo, deparou-se um contexto político e econômico que determina as condições de produção de discursos gerenciais, alinhados com a administração empresarial, bem como uma apolítica de silêncio a respeito da função política do gestor escolar.

\section{O programa de formação em serviço oferecido em 2017}

Não foi apresentado pela Secretaria de Educação, nas oportunidades em que se visitou sua sede, um memorial formal sobre processos formativos, uma proposta pedagógica ou similar. Assim, por meio da História Oral e da análise dos documentos, buscou-se reconstituir o programa pesquisado.

Segundo dados coletados nas entrevistas, antes de 2017 existiam movimentos formativos mais difusos e descontínuos. Mas a partir desse ano houve uma movimentação mais bem sistematizada, na oferta de formação em serviço na Rede. Esse formato, destinado ao que se chamou Trio Gestor (Gestor, Coordenador e Supervisor), com encontros regulares, foi implementado em 2017 e, a partir de 2018 passou a ter outro formato: em polos, com grupos menores.

Em 2017, a Secretaria Municipal de Educação do Município estudado implementou um Programa de Formação com todos os integrantes da equipe gestora escolar: gestores, professores coordenadores e vice-diretores. Desses encontros, segundo documentos, 13 contaram com a participação do Gestor Escolar.

Com o objetivo de sistematizar o processo investigativo, a análise foi categorizada, tanto dos documentos, quanto nas entrevistas, em três dimensões:

I - Estrutura: reconstituição da estrutura do Programa de Formação em Serviço de gestores escolares: objetivos, métodos, conteúdos e avaliação.

II - Epistemologia: identificação da linha epistemológica adotada nas referidas formações.

III - Discursos: identificação dos discursos presentes nos documentos e entrevistas e das políticas e ideologias constituintes desses discursos;

Segundo as entrevistas, o acesso à função de "Diretor Escolar" não está normatizado em legislação, nem se dá por concurso público. Os professores efetivos são indicados para essa função pelo Secretário de Educação. A Formadora 01 relatou que, até 2016, havia um processo de qualificação simples, em que o 
cargo poderia ser pleiteado mediante prova classificatória e apresentação de projeto, porém esse processo não teve continuidade.

Os gestores escolares entrevistados têm idade média entre 30 e 50 anos, e seu tempo médio de atuação médio no cargo é de 5 anos. Dos 3 Formadores, apenas 2 têm experiência como Gestor Escolar, e atuam em funções na Secretaria Municipal de Educação há 2 anos, 3 anos e 10 anos, respectivamente.

Tendo como critério sua relação com o Programa de Formação em Serviço, optou-se por entrevistar 3 profissionais da Secretaria de Educação do município estudado, convencionalmente categorizados como "Formadores", que em diferentes níveis participaram da idealização e da operacionalização do referido Programa.

Dentre esses Formadores, 3 ocupavam funções de primeiro e segundo escalão e exerciam ação indireta no sentido de sugerir e chancelar pautas. O terceiro, com função operacional, foi responsável pelo planejamento e coordenação dos encontros formativos oferecidos aos gestores escolares.

Observou-se que, paralelamente, no mesmo período, foi oferecido um Programa de Instrumentalização do Gestor Escolar com foco em gestão do tempo e gestão de resultados, promovido pela Fundação Leman. Em alguns momentos das entrevistas esse programa é mencionado pelos gestores.

\section{Análises}

I Estrutura: Reconstituição da estrutura do Programa de Formação em Serviço de gestores escolares: Objetivos, métodos, conteúdos e avaliação

Programa ou ações formativas?

Como ponto de partida, convencionou-se chamar de "Programa de Formação em Serviço", o objeto estudado nesse artigo; mas, conceitualmente, um "programa" tem objetivos amplos, associados ao conceito de efetividade, ou seja, tem como propósito gerar impacto em um campo também amplo. Por exemplo: "Aperfeiçoar a qualidade da aprendizagem da Rede Municipal de Ensino". Um programa é constituído de projetos que, articulados, viabilizam os objetivos do programa (ZOPPA, 2017).

Desse modo, a partir das entrevistas e documentos, concluiu-se que não foi formalizado um "programa" pela Rede de Ensino estudada, por conta da ausência dos elementos que assim o caracterizassem. Efetivamente, foram oferecidos aos gestores escolares, em 2017, na condição de formação em serviço, encontros formativos com temática de gestão.

Trata-se de uma ação recente, portanto em desenvolvimento. Segundo as entrevistas, foi muito bem recebida pelos gestores escolares, que a caracterizam como uma ação inovadora, da qual se sentiam felizes em fazer parte.

Ressalte-se que foi observado, nos gestores escolares e nos formadores, engajamento em suas atribuições, assim como dedicação e satisfação em realizar o trabalho educativo de gestão. Houve boa recepção em todos os locais, principalmente nas escolas, que apresentavam boas condições de conservação, limpeza e organização. Apresentavam também bom acolhimento a alunos e comunidade. 


\section{a) Objetivos}

Foi possível verificar, nas entrevistas e nos documentos, que os objetivos dos encontros formativos não passaram por um processo de discussão formal, nem houve ações que permitissem ao gestor escolar contribuir na constituição de objetivos. Não houve, também, processos de investigação com algum rigor técnico para fins de orientação das escolhas.

Não há indícios, nas entrevistas dos Formadores da Secretaria Municipal de Educação, de uma proposta pedagógica ou de um plano educativo mais amplo, no nível da Rede, que preceda a formação em serviço dos gestores escolares, em que eventualmente pudessem estar expressos objetivos.

Esse fator aponta um alienamento crítico dos idealizadores da formação em serviço frente ao papel do gestor escolar em relação à escola, no sentido de não definir de forma intencional e fundamentada as expectativas dos encontros formativos sobre a prática do gestor escolar, considerando-se, tanto os aspectos técnicos, quanto os políticos.

Segundo Morais (2016), não há fontes orais falsas, mas olhares e significados diferentes, cumprindo à História Oral informar mais sobre os significados do que sobre os acontecimentos. Sendo assim, nas entrevistas os Formadores indicaram que os objetivos eram decididos encontro a encontro, a partir das demandas trazidas pelos Supervisores, como se os encontros fossem celulares e independentes. O não dito (ORLANDI, 1999), neste caso, diz exatamente o contrário: há uma linha coerente e orgânica entre os encontros formativos, cujo objetivo central seria: dotar os gestores tecnicamente com instrumentos gerenciais para coordenação de ações e criação de sinergia da equipe com foco em resultados de aprendizagem, manifesta na formação ideológica das entrevistas e dos documentos.

b) Conteúdo

O conteúdo está bem definido nos documentos: Temas de Administração Geral; Liderança; Planejamento Estratégico; Indicadores; Eficiência; Eficácia; Gestão do tempo; Monitoramento, e Mediação de conflitos.

\section{c) Avaliação}

Conceitos gerenciais sobre eficiência, em referência ao processo - melhor resultado com o mínimo de recursos (BRASIL, 2009) e (BRASIL, 2013), foram utilizados como instrumento de avaliação em uma pesquisa de satisfação. Os resultados, porém, não foram considerados durante a execução dos encontros.

Sobre eficácia, que mede o sucesso dos objetivos ou metas (BRASIL, 2009) e (BRASIL, 2013), não há menção nos documentos. Há um relato contraditório entre duas Formadoras acerca de uma investigação nas escolas sobre mudança de comportamento dos gestores, a partir dos encontros formativos: uma diz que ocorre e outra diz que deveria ocorrer. Se houve, não se traduziu ou interferiu formalmente em algum registro avaliativo. Do ponto de vista lógico, seria improvável haver uma avaliação de impacto, ou dos objetivos, visto que não estão formalizados. Os dados orais “[...] fornecem visões diferentes sobre um 
determinado caso, e ao historiador cabe buscar a imparcialidade, amparando-se em diversas fontes de pesquisa." (MATOS, SENNA, 2011, p. 103).

Sobre efetividade, o conceito não pareceu em nenhum discurso ou documento, possivelmente por se tratar de um termo ainda pouco difundido fora do campo da gestão pública. Mede, por meio de indicadores, o impacto social das ações adotadas, portanto é mais abrangente que a eficácia (BRASIL,2009) e (BRASIL, 2013). Não há registro.

\section{d) Metodologia}

Observou-se, nos documentos cedidos e nos discursos, que, do ponto de vista metodológico, as formações partiram de competências gerais de liderança e recursos instrumentais de gestão para definir o conhecimento mobilizado nos encontros formativos.

Foi escolhida uma linha epistemológica com uma identidade bem definida, que se desenvolveu de forma linear, mas coerente internamente com os objetivos implícitos.

Não há uma definição clara das operações didáticas nos encontros, mas o conteúdo do documento cedido permite inferir que ocorreu uma disputa entre exposição, dinâmicas e agrupamentos procedimentais. Não há indícios de aprofundamento intencional em algum tema, nem durante os encontros, nem em outros momentos. Não foram cedidos registros reflexivos e nem há menção a ações semelhantes. Também não foi possível observar o impacto das sugestões nos encontros formativos, portanto é presumível que os gestores escolares não tiveram um papel de interação bem definido na organização dos encontros.

Não há registros de indicadores, pesquisas ou outros instrumentos que consideraram a prática ou o saber do Gestor Escolar para seleção do conhecimento a ser mobilizado, ou mesmo para sua organização didática.

Nos documentos, um dos gestores sugere uma visita aos locais de experiências práticas. Apesar da convergência epistemológica sobre o local, enquanto ambiente formativo elementar, não se observou nos documentos, nem nas entrevistas, registros ou menções de ações formativas nesse sentido.

Essencialmente, por conta de partir de um Gestor Escolar idealizado, os encontros formativos guardam características de formação normativa e prescritiva, inscrevendo-se no conceito de capacitação ou treinamento, em função, sobretudo, de alienar o gestor dos processos decisórios e alienar-se de uma epistemologia da prática. Assim, o Gestor Escolar está para formação em serviço como objeto, e não como sujeito de sua formação.

\section{Epistemologia: identificar a linha epistemológica adotada nas referidas formações}

Ainda que alienado de uma epistemologia da prática, foi mobilizado um Campo Epistemológico nos encontros formativos, conforme demarcação realizada. Porém, não figuraram, nos discursos de formadores e gestores escolares, conceitos fundantes de Gestão Escolar. Como visto nas entrevistas entre 
formadores e gestores Escolares, dois terços dos entrevistados não souberam indicar uma referência bibliográfica discutida nos encontros formativos.

Isso indica, como método de mediação, a socialização tutelada de conceitos, interpretações e experiências selecionadas pelos Formadores, sem uma investigação protagonizada pelos gestores escolares no Campo Epistemológico proposto que pudesse ser submetida a crítica e que produzisse reflexões diversas. Em termos mais objetivos, conforme registro em sugestões dos encontros, não há indícios de acesso a material teórico.

Nesse caso, essas observações permitem concluir que a relação do Gestor Escolar com o Campo Epistêmico, seja a epistemologia no campo da Administração Geral, seja uma epistemologia da prática, não se deu de forma crítica e nem refletida. Há, portanto, uma ruptura na relação de interdependência, ou de mútua influência, entre sujeito e conhecimento. O Gestor Escolar está, nesse processo formativo, como consumidor de conhecimento, inversamente ao sujeito epistêmico discutido por Becker (1999).

III Discursos: identificação de quais discursos estão presentes nos documentos e entrevistas e de quais politicas e ideologias estão constituidos esses discursos;

a) O que dizem os discursos

Segundo Barros (2015), é importante descrever o cenário em que são elaborados os discursos, as condições de produção (ORLANDI, 2011). Dessa forma, “[...] cabe, então, ao analista do discurso observar as condições de produção dos textos e remeter aquele enunciado a determinada formação discursiva" (BARROS, 2015, p. 83).

Para iniciar, há que se lembrar que perdura grande expectativa da sociedade com relação à escola como vetor de possibilidade de mudança social, tanto para o indivíduo quanto para a própria sociedade (MACEDO, 2016). Está também popularizada a migração da discussão de quantidade para qualidade como etapa após exitoso processo de universalização do ensino, a qual está identificada em resultados de avaliações externas (BIEST, 2009).

Desde a década de 1960, dissemina-se a ideia de que o Estado não é capaz de operar com qualidade os serviços prestados, seja por corrupção orgânica, seja por ineficiência. (BRESSER-PEREIRA, 2007). Essa incapacidade é reforçada atualmente por conta de uma conjuntura de fragilidade econômica e política.

Nessa circunstância, a alternativa para o Estado seria tornar-se enxuto, eficiente e eficaz, e seu gerenciamento precisaria demandar conhecimento especializado, tendo no controle social a melhor ferramenta para tencionar a qualidade dos serviços prestados. Para a escola, além do fenômeno "accountability, a gestão participativa, identificada como democrática, seria a melhor metodologia de gestão para aprimoramento da qualidade (LIMA, 2014) e (LIMA 2014).

Hoje também goza de certo glamour a figura do líder sob a ótica carismática de fazer a diferença e do gestor na perspectiva técnica, de deter competências para resolver problemas, gerir pessoas em favor de um projeto coletivo de qualidade e garantir resultados. No caso do Gestor Escolar, garantir resultados de aprendizagem (BALL, 2014). 
Essas conjunturas políticas, econômicas e culturais estão expressas nos discursos dos gestores escolares e formadores. A qualidade como objetivo coletivo e a obsessão por resultados, admitindo os índices nacionais e internacionais como definidores de qualidade, constituem marcos referenciais, mesmo na educação infantil, cujas premissas pedagógicas estão mais associadas aos processos. Há valorização da liderança, das competências estratégicas, e o método gerencial é considerado o único possível. Valoriza-se também a gestão de pessoas como potência para afirmação de resultados. O planejamento estratégico, por sua vez, é visto como recurso para obter o máximo de rendimento com recursos escassos, e o acesso da comunidade à escola e sua participação nas frentes escolares constituem expressão democrática.

\section{b) Ideologia}

A principal ideologia, sequer aparece como conceito, nem em documentos, nem nas entrevistas, é a neoliberal. O neoliberalismo prevê o livre desenvolvimento econômico da sociedade como sintoma de desenvolvimento social. Fica indefinido se o desenvolvimento econômico é meio ou fim, se uma sociedade menos desigual seria o objetivo ou apenas uma colateralidade eventual. O neoliberalismo é uma estratégia capitalista, que propõe o Estado Mínimo, e o mínimo é justificado economicamente em uma relação custo benefício.

O sistema gerencial é uma estratégia operacional neoliberal. Assenta-se em princípios econômicos das ações do Estado, ou seja, o Estado deve organizar-se de forma tal, que com mínimos recursos realize o melhor possível, contribuindo assim para consecução e aperfeiçoamento dos resultados postos como meta.

Embora o Diretor Escolar seja chamado de gestor, a partir da Contribuição Federal de 1988 e da LDB de 1996, como tradução de uma ação de liderança democrática e, portanto, de natureza política, crítica e intencional, a prática do gestor, efetivamente, está intimamente associado à chamada Administração empresarial. O Gestor Escolar ocupa função de Gerente Escolar.

O gerente não tem papel crítico. Cabe-lhe realizar objetivos centralizados por escalões superiores, criar sinergia em torno de um projeto que assume como legítimo e de interesse coletivo, e garantir e responsabilizar-se por resultados que foram propostos por terceiros. O Gerente é um especialista com repertório técnico em gestão. Consciente ou não, de acordo ou não, ele cumpre e faz cumprir uma política da qual está alienado.

Talvez a principal ideologia passível de inferência seja a disseminação da crença de que a Gestão Gerencial de natureza econômica é a única possível. E talvez também a crença de que questões como crítica investigação teórica, emancipação e autonomia nas decisões estruturantes sejam discursos adjetivados como filosóficos - pejorativamente -, desvinculados da prática e, portanto inviáveis para a construção da qualidade predeterminada. Segundo Orlandi, (2005, p. 11), a “[...] memória discursiva, o já-dito que torna possível todo o dizer. As pessoas são filiadas a um saber discursivo que não se aprende, mas que produz seus efeitos por intermédio da ideologia e do inconsciente."

Quando se assume que o Diretor Escolar migrou para Gestor Escolar e agora migra para Gerente Escolar, segundo o pensamento Foucaultiano, admite-se que esse processo não se dá apenas por conta de uma evolução administrativa, mas por um conjunto complexo de relações social que permitem a produção 
de novos discursos que, combinando-se com outros discursos, produzem mudança no contexto (FERREIRA, TRAVERSINI, 2013).

\section{Considerações finais}

A investigação do Programa de Formação em Serviço remeteu a três conclusões.

A primeira delas refere-se à presença de um discurso estritamente alinhado com a política de gestão pública gerencial e economicista, fundada na política internacional de recomposição capitalista, chamada neoliberal.

A segunda conclusão aponta a negação institucional do Gestor Escolar, sua condição de sujeito e protagonista da formação em serviço, marcada pela inexistência de instrumentos investigativos sobre conhecimento produzido por ele. As condições psicossociais que determinam suas escolhas profissionais tampouco são instrumentos de participação em processos decisórios na seleção de objetivos, metodologias e conteúdos de formação.

A terceira conclusão revela uma ruptura epistemológica entre os campos técnicos e político da Gestão Escolar, no sentido da mobilização de conhecimentos instrumentais alienados de uma reflexão contextual sobre função política do gestor.

Meyhi (2006) alerta para o risco de se tomar a História Oral por História, quando se prescinde do devido tratamento metodológico: as análises e inferências do pesquisador. Dessa forma, esta análise permite assumir que o conjunto das entrevistas conta uma história, da qual se faz parte, sobre os processos formativos oferecidos aos gestores escolares, e nessa história são identificados: condições de produção, formações discursivas e discursos.

Na conjuntura da formação em serviço, ainda que não tenha sido objeto de investigação da pesquisa aqui relatada, evidenciou-se a presença de tensão entre aspectos técnicos e políticos da Gestão Escolar. Apresentam-se, agora, considerações sobre os discursos a respeito dessa problemática.

O primeiro ponto sobre a Gestão Escolar que pede atenção é, por um lado, certa radicalização radical, no sentido filosófico de Saviani (1980) - sobre a Teoria Geral de Administração, na perspectiva de que nesse campo se encerra o próprio espírito capitalista: exploração, acúmulo de capital e conservação da desigualdade social. Esse discurso está presente em um artigo do professor Paro (2009), que discute historicamente o papel de José Quirino Ribeiro como percursor da discussão sobre Administração escolar. Esse artigo apresenta essa característica do discurso crítico sobre o tema de forma geral (SILVA JÚNIOR, 1990), (SILVA JÚNIOR, 2015), (PARO, 2010) e (PARO, 2015). 


\begin{abstract}
A intenção, pois, de aplicar na escola os princípios de produção que funcionam nas empresas em geral não é recente, mas tem-se exacerbado ultimamente, configurando um crescente assalto da lógica empresarial capitalista sobre políticas educacionais e, em especial, sobre Gestão Escolar. [...] Ou como a formação de gestores, capitaneadas por pessoas e instituições afinadas com interesses de empresas capitalistas e por ideias e soluções transplantadas acriticamente da lógica e da realidade do mercado (PARO, 2015, p. 104).
\end{abstract}

Não em defesa do capitalismo, mas relativizando o papel da Administração, seria impossível imaginar a Gestão Escolar, na ausência hoje de uma disciplina própria, totalmente desassociada da Administração, porque na Administração está a gênese da gestão. Não se poderia presumir como racional, frente às efetivas demandas da prática, supor que seja possível Gestar (conceber) ou Gerir (manter) aspectos organizacionais de uma instituição que, pela natureza social, dispense o conhecimento técnico.

Libâneo (2017), na obra panorâmica intitulada “Organização e Gestão da Escola: teoria e Prática”, estabelece um discurso que transige com elementos instrumentais da administração, sem perder o enfoque educativo específico e crítico.

A intenção, aqui, é contextualizar o permanente discurso assumido nesta pesquisa sobre a indissociabilidade entre conhecimento técnico e conhecimento político (PARO, 2015) e (RIOS, 2009). Nessa relação, constantemente se observa latente a temeridade de que a sedução técnica/instrumental, por sua natureza prática, assuma papel central nos processos decisórios de gestão, confundindo meio com finalidade, de tal forma que esvaneça o sentido educativo, tão distinto do sentido empresarial.

É possível apontar, pelo volume de exemplos, perda de identidade no discurso de gestão educativa. Por exemplo, hoje é chamada de escola inovadora aquela organização que promove formas diversificadas de construir conhecimento. Mas inovação é um conceito que compõe o repertório estratégico das empresas para promover competitividade em um contexto de luta permanente por mercado: inovar é sinônimo de sobrevivência. Esta é a origem e a finalidade primeira do conceito de inovação, como mostra um breve panorama investigativo sobre o tema "planejamento estratégico" (GESTÃO E NEGÓCIOS, 2018), (LÜCK, 2000), (VASCONCELLOS FILHO, 1998).

Outros exemplos são a utilização de indicadores para mapear a qualidade da educação ou adoção de missão, visão e valores. Nessa mesma seara, a Gestão Democrática, que guarda estreito alinhamento com o pressuposto político ideológico corporativo, no campo de Gestão de Pessoas, visa criar engajamento e autonomia no campo de trabalho, fazendo crer, por meio de estratégias pseudo-participativas, que o colaborador operacional é também sujeito de poder, quando na verdade se presta a viabilizar objetivos externos

O ponto é que a Gestão Pública e, por consequência, a Gestão Escolar, adotou saberes administrativos desenvolvidos e cultivados em ambiente corporativo e com objetivos corporativos, cuja 
finalidade elementar é gerar lucro e garantir a sobrevivência para as empresas (BRASIL, 2009) e (BRASIL, 2013).

Esse ponto é ainda mais crítico, porque, tanto no universo corporativo, quanto no educativo, as lideranças operacionais, de modo geral, estão em baixos escalões, alienados da crítica e dos processos decisórios, cumprindo-lhes disseminar ideologias que criem sinergia coletiva em favor de finalidades alheias.

É um paradoxo a identificação do Gestor Escolar com aquelas lideranças operacionais acima descritas, porque essa condição é justamente a negação da sua distinção conceitual, a prática política, crítica e refletida.

As considerações acima têm o propósito de contextualizar a formação em serviço do Gestor Escolar em um cenário técnico, predominantemente corporativo, e em um cenário político hegemonicamente neoliberal.

O Gestor Escolar, para a formação em serviço, está posto como liderança estratégica - com toda a carga de competências que o conceito carrega. Seu desafio é gerenciar as diferentes dimensões de gestão que corporificam a escola, de forma eficiente e eficaz, propondo estratégias e metas que garantam resultados, responsabilizando-se pelo sucesso ou insucesso da unidade escolar. Esse discurso está apresentado nas dimensões de gestão discutidas por Lück (2009).

No objeto concreto, o processo de formação em serviço oferecido aos gestores escolares por uma rede municipal de ensino, no ano letivo de 2017, conforme se pode observar no desenvolvimento da pesquisa de campo, a partir da análise dos dados coletados, não foram identificadas ações formalizadas sobre processo de mediação para construção de conhecimento político sobre práticas de gestão. No entanto, não se quer afirmar, aqui, que não tenha havido. Potencialmente, as interações formativas sujeitam os interlocutores a relações de poder e, consequentemente, à formação política, o que não se observa nos registros e nos discursos é que tenha havido intencionalidade institucional ou mobilização de Campos Epistêmicos que tratem politicamente da Gestão Escolar.

Os resultados da pesquisa remetem a novas questões racionais como, a quem e por que poderia interessar que o Gestor Escolar seja sujeito de uma formação política, de modo a problematizar, em sua prática formativa, temáticas como as contradições sociais presentes nas escolas, a democracia como processo formativo emancipatório ou a função social da escola, estabelecendo críticas à qualidade predeterminada em outras esferas que antecedem o campo de autonomia da escola.

Tanto para Shulman (2014), quando interroga sobre o cerne da prática educativa, quanto para Gatti, o fato educacional é um fato social, portanto eminentemente político. "[...] não é uma questão que se restringe a técnica, muito menos às tecnologias. Não é uma questão formal. Ela implica perguntar-se por significados históricos na compreensão dos processos educativos" (GATTI, 2009, p. 91). "Mas, o que há, enfim, de tão perigoso no fato de as pessoas falarem e de seus discursos proliferarem indefinidamente? Onde, afinal, está o perigo?” (FOUCAULT, 1996, p. 8).

Com isso, queremos destacar o silêncio. O silêncio sobre o Gestor Escolar epistêmico e o Gestor Escolar Político é, em si, um discurso: o não dito na política do silêncio (ORLANDI, 1999). Essa temática 
está silenciada por processos de interdição (FOUCAULT, 1966), que dizem respeito a um contexto histórico que ordena os discursos, e o discurso de formação política não está entre eles.

[...] ninguém entrará na ordem do discurso se não satisfazer a certas exigências ou se não for, de início, qualificado para fazê-lo. Mais precisamente: nem todas as regiões do discurso são igualmente abertas e penetráveis; algumas são altamente proibidas [...], enquanto outras parecem quase abertas a todos os ventos e postas, sem restrição prévia, à disposição de cada sujeito que fala (FOUCAULT, 1996, p. 37).

A temática do Gestor Político, hoje uma abordagem com contornos de irracionalidade, de alienação da realidade, é adjetivada como filosofia, no sentido popularmente pejorativo que lhe atribui traços românticos e oníricos. Portanto, o campo político está interditado no discurso da formação em serviço, porque não tem propriedades que contribuam para práticas gerenciais, voltadas a resultados aferidos e balizadas por indicadores externos, definidores de qualidade.

A explicitação e a crítica das atuais funções do diretor devem ter presente a contradição que consiste em se ter um diretor cuja formação, atribuições e atuação prática foram concebidos para um papel de simples gerente, sem nenhuma explicitação nem reflexão a respeito de suas características de agente político (PARO, 2015, p. 105).

Para concluir, é possível afirmar que há uma relação coerente e orgânica entre o contexto políticoideológico e as práticas de Formação em Serviço oferecidas ao Gestor Escolar da rede de ensino investigada. Há potencialmente uma dinâmica de racionalidade entre as demandas profissionais, jurídicas e econômicas da gestão pública da rede de ensino estudada e o conhecimento mediado entre os gestores escolares.

O problema que imediatamente se coloca é: na melhor acepção de utopia, em um cenário de permanente pressão por eficiência e resultados como tradução de qualidade, será possível, razoável e sustentável idealizar uma formação de gestores escolares que promova a mediação com o complexo Campo Epistemológico de Gestão Escolar, com efetivas expectativas de uma atuação política, crítica e refletida do Gestor Escolar?

\section{Referências}

BALL, S. J. Performatividades e Fabricações na Economia Educacional: rumo a uma sociedade performativa. Educação e Realidade. V. 35, N.2. Maio/agosto. 2010. Disponível em: $<$ http://seer.ufrgs.br/index.php/educacaoerealidade/article/view/15865/9445>

BARROS, T.H. Uma trajetória da Arquivística a partir da Análise do Discurso: inflexões histórico-conceituais [online]. São Paulo: Editora UNESP; São Paulo: Cultura Acadêmica, 2015.

BECKER, F. O sujeito do conhecimento: Contribuições da epistemologia genética. Educação e Realidade. Janeiro/Junho. 1999. Disponível em: <file:///C:/Users/Marcelo/Downloads/55807-228025-1PB\%20(1).pdf $>$.

BIEST, G. Boa educação na era da mensuração. Artigo inicialmente publicado em Educational Assessment, Evaluation and Accountability - v. 21, n. 1, p. 33-46, fev. 2009.

BRASIL. Senado Federal. Lei de Diretrizeses e Bases da Educação Nacional: no 9394/96. Brasília: 1996. 
BRASIL. Guia referencial para medição de desempenho e manual para construção de indicadores. Secretaria de Estão Pública. Ministério do Planejamento. Governo Federal. 2009.

Disponível em:

<http://www.gespublica.gov.br/sites/default/files/documentos/guia indicadores jun2010.pdf $>$.

BRASIL. Manual de Orientação para Gestão de Desempenho. Secretaria de Gestão Pública. Ministério do Planejamento. Governo Federal. 2013. Disponível em:

$<$ http://www.planejamento.gov.br/assuntos/gestao-publica/arquivos-

epublicacoes/manual orientacao para gestao desempenho.pdf/view $>$.

BRASIL. Constituição (1988). Constituição da República Federativa do Brasil. Disponível em: < http://www.gespublica.gov.br/sites/default/files/documentos/guia indicadores_jun2010.pdf $>$.

BRESSER-PEREIRA, L. C. Burocracia pública na construção do Brasil. Revista de Sociologia e Politica, 2007, n. 28: 9-30.

FOUCAULT, M. A ordem do discurso: aula inaugural no Collège de France, pronunciada em 2 de dezembro de 1970. Campinas: Loyola, 1996.

GATTI. B. A. Formação continuada de professores: a questão psicossocial. Cadernos de Pesquisa, n. 119, p. 191-204, julho/ 2003.

Disponível em: < http://www.scielo.com.br/pdf/cp/n119/n119a10.pdf>. Acesso em 25 de ago de 2017.

GESTÃO E NEGÓCIOS. Planejamento estratégico. Acesso em 2018. Disponível:

< $\underline{\text { https://pt.scribd.com/document/356133340/Planejamento-Estrategico-QI-pdf }>}$

GREGOLIN, M.R.V. A análise do discurso: conceitos e aplicações. Alfa: São Paulo. 39: 13-21,1995.

ICHIKAWA, E. Y. O grupo de estudos organizacionais. Uma história entre outras histórias. Revista de Estudos Organizacionais e Sociedade. Núcleo de Estudos Organizacionais e Sociedade. FACE/UFMG. Belo Horizonte. N.1. Junho. 2004.

ICHIKAWA, E. Y.; SANTOS, L. W. Contribuições da história oral à pesquisa organizacional. In: SILVA, A. B.; GODOI, C. K.; MELLO, R. B. (Org.). Pesquisa qualitativa em estudos organizacionais: paradigmas, estratégias e métodos. São Paulo: Saraiva, 2006. p. 185-209.

INDICADORES SOCIAIS: PASSADO, PRESENTE E FUTURO/ IBGE, Gerência de Biblioteca e Acervos Especiais. Organizado por André Simões e Antônio Carlos Alckmin. - Rio de Janeiro: IBGE, 2017.

INDICADORES DA QUALIDADE NA EDUCAÇÃO / Ação Educativa, UNICEF, PNUD, INEP, SEB/MEC (coordenadores) - São Paulo: Ação Educativa, 2013, 4. ed. Ampliada, p. 92.

LIBÂNEO. J. C. Organização e Gestão da Escola: teoria e Prática. Revisada e Ampliada. 6. ed. São Paulo: Heccus Editora. 2017.

LIMA, L. C. A gestão democrática das escolas: do autogoverno à ascensão de uma pós-democracia gestionária? Educ. Soc., Campinas, v. 35, nº 129, p. 1067-1083, out.-dez., 2014.

LÜCK. H. A evolução da gestão educacional a partir de mudança paradigmática. CEDHAP - Centro de desenvolvimento humano aplicado. Revista Gestão em Rede, nº. 3, nov, 1997, p. 13-18.

LÜCK. H. Aplicação do planejamento estratégico na escola. Revista Gestão em Rede, nº. 19, abril, 2000, p. 813.

LÜCK. H. Dimensões de gestão escolar e suas competências. Curitiba: Positivo, 2009. 
LÜCK. H. Avaliação e Monitoramento do Trabalho Educacional. Série Cadernos de Gestão. Petrópolis, RJ: Vozes. 2013.

MACEDO, E. Base Nacional Curricular Comum: a falsa oposição entre conhecimento para fazer algo e conhecimento em si. Educação em Revista. Belo Horizonte. V.32. no 02.p. 45-67. Abril-Junho 2016. Disponível em:

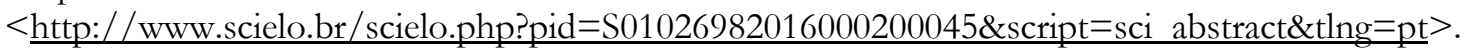

MATOS, J. S. SENNA, A. K. História oral como fonte: problemas e métodos. História/E, Rio Grande, 2 (1): 95-108, 2011. Disponível em: < http://www.seer.furg.br/hist/article/view/2395/1286>. Acesso em 05 de jan de 2018.

MEIIHY, J. C. Definindo história oral e memória. Cadernos CERU - No 5 - Série 2 - 1994.

MEIIHY, J. C. Os novos rumos da história oral: o caso brasileiro. Revista de História 155. 2. 2006. 191 203.

MORAIS, P. T. Apontamentos sobre a história oral como técnica, método e metodologia de pesquisa. Relevâncias - Revista de Geografia. São Paulo. Ano 1. no 1. Jan./jun de 2016.

ORLANDI. E. P. Discurso, imaginário social e conhecimento. Em Aberto, Brasília, ano 14, n.61, jan./mar. 1994.

ORLANDI. E. P. Análise de Discurso: princípios e procedimentos. Campinas (SP): Pontes; 1999.

ORLANDI.E. P. Análise de Discurso - Princípios \& Procedimentos. 3. ed. São Paulo: Pontes, 2001.

ORLANDI. E. P. Michael Pêcheux e análise do discurso. Estudos de Linguagem. Vitória da Conquista. n 1. p.9-13. Junho. 2005.

PARO, V. H. A educação, a política e a administração: reflexões sobre a prática do diretor de escola. Educação e Pesquisa, São Paulo, v. 36, n.3, p. 763-778, set./dez. 2010.

PARO, V. H. Diretor Escolar: gerente ou educador? São Paulo: Cortez, 2015.

RIOS, T. A. A educação que queremos: projeto político-pedagógico. Seminário de Atualização DidáticoPedagógica. PROGRAD-CADIPE- Universidade de São Francisco. Bragança Paulista, EDUSF. Secretaria Municipal da Educação de Piracicaba, maio de 2001.

RIOS, T. A. Ética e competência. 20.ed. São Paulo: Cortez, 2009.

SANTAGADA. S. Indicadores sociais: Contexto social e breve histórico. Revistas FEE. v. 20, n. 4.1993. Disponível em: < https://revistas.fee.tche.br/index.php/indicadores/article/view/758/1013 >.

SAVIANI, D. Educação, do senso comum à consciência filosófica. $12^{\circ}$ ed. São Paulo: Autores associados, 1980. SHULMAN, L.S. Conhecimento e ensino: fundamentos para a nova reforma. Cadernos Cenpec. São Paulo. v.4 - n.2 - p.196-229, dez. 2014.

SILVA JÚNIOR, C. A. A escola pública como local de trabalho. São Paulo: Cortez: Autores Associados. 1990.

VASCONCELLOS FILHO, P. Afinal, o que é planejamento estratégico? Rev. Adm. Empres vol.18 no.2 São Paulo Apr./June 1978. Disponível em: < http://dx.doi.org/10.1590/S0034-75901978000200002>.

ZOPPA, A. Projetos, Sub-projetos, Programas e Portfólios - como diferencia-los e entendê-los. Revista PMKB. 06/11/2017. Disponível em: < https://pmkb.com.br/artigos/projetos-sub-projetosprogramas-e-portfolios-2/>. 
c-ISSN: $2525-3514$

Recebido em 19 jul. 2019 / Aprovado em: 18 nov. 2019

\section{Para referenciar este texto:}

NASCIMENTO, Marcelo do; OLIVEIRA, Alessandro Luiz de; ABDALA, Rachel Duarte. Análise do discurso na formação em serviço dos gestores escolares. Cadernos de Pós-graduacãá, São Paulo, v. 18, n. 2, p. 176-190, jul./dez. 2019. Disponível em: < https://doi.org/10.5585/cpg.v18n2.14468>. 